\title{
A Review on Functionally Gradient Materials (FGMs) and Their Applications
}

\author{
Himasekhar Sai B. $\mathbf{V}^{+*}$ \\ †Department of Mechanical Engineering, Chaitanya Bharathi Institute of Technology, Hyderabad, India \\ Received 25 Nov 2017, Accepted 26 Jan 2018, Available online 05 Feb 2018, Vol.8, No.1 (Jan/Feb 2018)
}

\begin{abstract}
Functionally gradient materials (FGM) are innovative materials in which final properties varies gradually with dimensions. It is the recent development in traditional composite materials which retains their strengths and eliminates their weaknesses. It can be formed by varying chemical composition, microstructure or design attributes from one end to other as per requirement. This feature allows FGM to have best material properties in required quantities only where it is needed. In this study, an overview of fabrication processes, area of application, some recent research studies and the need to focus more research effort on improving the most promising FGM fabrication method (solid freeform SFF and Friction Stir Welding) is presented. Improving the performance of SFF and Friction Stir Processing processes and extensive studies on material characterization on components produced will go a long way in bringing down the manufacturing cost of FGM and increase productivity in this regard.
\end{abstract}

Keywords: Applications of FGM, Functionally graded material, Material characterization of FGM, Processing technique of FGM

\section{Introduction}

The first concept of Functionally Graded Materials (FGMs) was proposed in 1987 by [Niino et al] during a space plane project at the National Aerospace Laboratory of Japan. there is no such material existing in nature. Pure metals are of little use in engineering applications because of the demand of conflicting property requirement. For example, an application may require a material that is hard as well as ductile, To solve this problem, combination (in molten state) of one metal with other metals or non-metals is used.

This combination of materials in the molten state is termed alloying (recently referred to as conventional alloying) that gives a property that is different from the parent materials. Bronze, alloy of copper and tin, was the first alloy that appears in human history. Bronze really impacted the world at that time, it was a landmark in human achievement and it is tagged the 'Bronze Age' in about 4000 BC. Since then, man has been experimenting with one form of alloy or the other with the sole reason of improving properties of material. There is limit to which a material can be dissolved in a solution of another material because of thermodynamic equilibrium limit [B. Craig et al]. When more quantity of the alloying material is

*Corresponding author's ORCID ID: 0000-0002-5688-6643 DOI: https://doi.org/10.14741/ijcet.v8i01.10894 desired, then the traditional alloying cannot be used. Another limitation of conventional alloying is when alloying two dissimilar materials with wide apart melting temperatures; it becomes prohibitive to combine these materials through this process. Powdered Metallurgy (PM) is another method of producing part that cannot be produced through the conventional alloying, as alloys are produced in powdered form and some of the problems associated with the conventional alloying are overcome. Despite the excellent characteristics of powdered metallurgy, there exist some limitations, which include: intricate shapes and features that cannot be produced using PM; the parts are porous and have poor strength [R. K. Rajput et al]. Although these limitations are of advantage to some applications (e.g. filter and non structural applications) but are detrimental to others.

Another method of producing materials with combination of properties is by combining materials in solid state, which is referred to as composite material. Composite material are a class of advanced material, made up of one or more materials combined in solid states with distinct physical and chemical properties. Composite material offers an excellent combination of properties which are different from the individual parent materials and are also lighter in weight. Wood is a composite material from nature which consists of cellulose in a matrix of lignin [D. Hon et al]. Composite materials will fail under extreme working conditions through a process called 
delamination (separation of fibers from the matrix) [S. S. Wang et $a l]$. This can happen for example, in high temperature application where two metals with different coefficient of expansion are used. To solve this problem, researchers in Japan in the mid 1980s, confronted with this challenge in an hypersonic space plane project requiring a thermal barrier (with outside temperature of $2000 \mathrm{~K}$ and inside temperature of $1000 \mathrm{~K}$ across less than $10 \mathrm{~mm}$ thickness), came up with a novel material called Functionally Graded Material (FGM) [M. Niino et al, T. Hirai et al].

Functionally Graded Material (FGM), a revolutionary material, belongs to a class of advanced materials with varying properties over a changing dimension [P. Shanmugavel et al, A. A. Atai et al]. Functionally graded materials occur in nature as bones, teeth etc. [R. Knoppers et al], nature designed this materials to meet their expected service requirements. This idea is emulated from nature to solve engineering problem the same way artificial neural network is used to emulate human brain. Functionally graded material, eliminates the sharp interfaces existing in composite material which is where failure is initiated [M. Ivosevic et al]. It replaces this sharp interface with a gradient interface which produces smooth transition from one material to the next [M. Niino et al, T. Hirai et al]. One unique characteristics of FGM is the ability to tailor a material for specific application [P. Shanmugavel et $a l]$.

There are different kinds of fabrication processes for producing functionally graded materials. Functionally graded materials can be divided into two broad groups namely: thin and bulk FGM. Thin FGM are relatively thin sections or thin surface coating, while the bulk FGM are volume of materials which require more labour intensive processes. Thin section or surface coating FGM are produced by Physical or Chemical Vapour Deposition (PVD/CVD), Plasma Spraying, Self-propagating High- temperature Synthesis (SHS) etc [M. Ivosevic et al]. Bulk FGM is produced using powder metallurgy technique, centrifugal casting method, solid freeform technology etc [R. Knoppers et $a l]$. Functionally graded materials find their applications in aerospace, automobile, medicine, sport, energy, sensors, optoelectronic etc. As the fabrication process is improved, cost of powder is reduced and the overall process cost is reduced, hence expanding the application of FGM. Owing to the importance of FGM, there are lots of research efforts at improving the material processing, fabrication processing and properties of the FGM.

This paper presents an overview of fabrication methods and application areas of functionally graded materials. Some research works on functionally graded materials in recent times are presented and the future research needs are proposed. The rest of the paper is organized as follows: processing techniques of functionally graded materials is presented in section II, section III gives areas of application of FGM. Recent research efforts are presented in section IV, while future research needs is presented in section $\mathrm{V}$. The paper ends with concluding remarks in section VI.
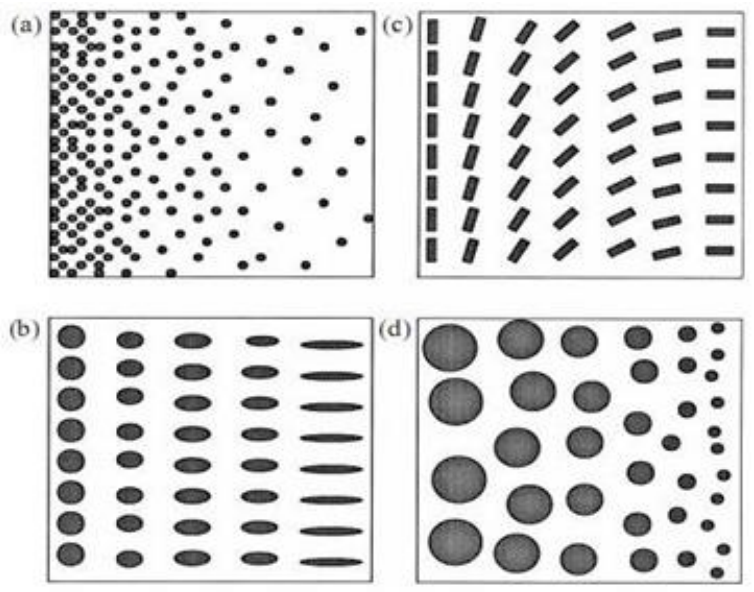

Figure. 1: Different types of functionally graded composites. Gradient of: (a) fraction, (b) shape, (c) orientation, and (d) size

\section{Processing Techniques of Functionally Graded Materials (FGM)}

Thin functionally graded materials are usually in the form of surface coatings, there are a wide range of surface deposition processes to choose from depending on the service requirement from the process.

\section{A. Vapour Deposition Technique}

There are different types of vapour deposition techniques, they include: sputter deposition, Chemical Vapour Deposition (CVD) and Physical Vapour Deposition (PVD). These vapour deposition methods are used to deposit functionally graded surface coatings and they give excellent microstructure, but they can only be used for depositing thin surface coating. They are energy intensive and produce poisonous gases as their byproducts [J. F. Groves et al].

Other methods used in producing functionally graded coating include: plasma spraying, electrodeposition, electrophoretic, Ion Beam Assisted Deposition (IBAD), Self-Propagating Hightemperature Synthesis (SHS), etc [R. Knoppers et al]. All the above mentioned processes cannot be used to produce bulk FGM because they are generally slow and energy intensive, therefore they are uneconomical to be used in producing bulk FGM. Some of the fabrication methods for producing bulk functionally graded materials are as follows:

\section{B. Powder Metallurgy (PM)}

Powder metallurgy (PM) technique is used to produce functionally graded material [M. M. Nemat-Alla et al, F. 
Watari et al] through three basic steps namely: weighing and mixing of powder according to the predesigned spatial distribution as dictated by the functional requirement, stacking and ramming of the premixed-powders, and finally sintering [J. Zhu et $a l$. PM technique gives rise to a stepwise structure. If continuous structure is desired, then centrifugal method is used.

\section{Centrifugal Method}

Centrifugal method is similar to centrifugal casting where the force of gravity is used through spinning of the mould to form bulk functionally graded material [Y. Watanabe et al]. The graded material is produced in this way because of the difference in material densities and the spinning of the mould. There are other similar processes like centrifugal method in the literature (e.g. gravity method, etc.). Although continuous grading can be achieved using centrifugal method but only cylindrical shapes can be formed. Another problem of centrifugal method is that there is limit to which type of gradient can be produced [B. Kieback et al] because the gradient is formed through natural process (centrifugal force and density difference). To solve these problems, researchers are using alternative manufacturing method known as solid freeform.

\section{Solid Freeform (SFF) Fabrication Method}

Solid freeform is an additive manufacturing process that offers lots of advantages that include: higher speed of production, less energy intensive, maximum material utilization, ability to produce complex shapes and design freedom as parts are produced directly from CAD (e.g. AutoCAD) data [X. Lin et al]. SFF involves five basic steps [M. A. Boboulos et $a l]$ : generation of CAD data from the software like AutoCAD, Solid edge etc, conversion of the CAD data to Standard Triangulation Language (STL) file, slicing of the STL into two dimensional cross-section profiles, building of the component layer by layer, and lastly removal and finishing. There are various types of SFF technologies, laser based processes are mostly employed in fabrication of functionally graded materials [D. W. Hutmacher et al]. Laser based SFF process for FGM [Y. T. Pei et al, W. Jiang et al] include: laser cladding based method [W. Liu et al, K. A. Mumtaz et al, T. R. Jackson et al, X. C. Li, J. Stampfl et al, V. E. Beal et $a I$, Selective Laser Sintering (SLS) [M. Erdal et al, H. Chung et al], 3-D Printing (3-DP) [T. R. Jackson et $a l]$, and Selective Laser Melting (SLM) [K. A. Mumtaz et $a l]$. Laser cladding based system and selective laser melting are capable of producing fully dense components. Solid freeform provide manufacturing flexibility amongst other advantages but the technology is characterized by poor surface finish making it necessary to carry out a secondary finishing operation. There are lots of research efforts in this direction to improve surface finish, dimensional accuracy etc.

\section{E. Friction Stir Processing (FSP)}

Friction Stir Processing (FSP), a solid state processing technique that uses the same principle as friction stir welding (FSW) which has been attracted for the last few decades due to its several advantages in which high strength alloys can also be joined, whereas in conventional fusion welding it is difficult. The FSP, a non-consumable joining technique which has a rotating tool with a pin and a shoulder plunges onto the surface and moves transversely along the path. The rotating tool impels the viscoplastic deformation at the interface between the tool and work piece, causing heat generation which softens the material without reaching the melting point. The material flow is stirred and forged under shoulder pressure during the process. The process FSW was invented by The Welding Institute of technology (TWI) of UK in 1991.

Friction Stir Welding provides the defect free welds which includes hot cracking, distortion etc. The joining process occurs below the melting temperature of weld material. No toxic fumes or arc flashes has been evolved in this process unlike in the fusion welding process.

There are other fabrication methods for functionally graded materials; readers can refer to the review studies by [Kieback and Neubrand; and Gasik et $a l]$. These authors presented comprehensive processing techniques of functionally graded materials.

\section{Areas of Application of FGM}

Some of the applications of functionally graded materials are highlighted below:

\section{A. Aerospace}

Functionally graded materials can withstand very high thermal gradient, this makes it suitable for use in structures and space plane body, rocket engine component etc [L. Marin et al]. If processing technique is improved, FGM are promising and can be used in wider areas of aerospace.

\section{B. Medicine}

Living tissues like bones and teeth are characterized as functionally graded material from nature [W. Pompea et $a l]$, to replace these tissues, a compatible material is needed that will serve the purpose of the original bio-tissue. The ideal candidate for this application is functionally graded material. FGM has find wide range of application in dental [S. Matsuo et $a$ ] and orthopedic applications for teeth and bone replacement [F. Watari et $a l]$. 


\section{Defense}

One of the most important characteristics of functionally graded material is the ability to inhibit crack propagation. This property makes it useful in defense application, as a penetration resistant materials used for armour plates and bullet-proof vests [L. Lu et al].

\section{Energy}

FGM are used in energy conversion devices. They also provide thermal barrier and are used as protective coating on turbine blades in gas turbine engine [E. Müller et al, M. Niino et $a l$.

\section{E. Optoelectronics}

FGM also finds its application in optoelectronics as graded refractive index materials and in audio-video discs magnetic storage media.

Other areas of application are: cutting tool insert coating, automobile engine components, nuclear reactor components, turbine blade, heat exchanger, Tribology, sensors, fire retardant doors, etc [M. Malinina et $a l]$. The list is endless and more application is springing up as the processing technology, cost of production and properties of FMG improve [B. Woodward et al].

\section{Recent Research Efforts in FGM}

Lots of studies have been conducted on behavior of functionally graded materials and the literature $\mathrm{i}$ transverse loading was investigated by Woodward and Kashtalyan et al and property estimation study was conducted by $\mathrm{Lu}$ et al., [L. Lu et al]. A comprehensive review on performance of FGM was published in 2007 by Birman and Byrd, [V. Birman et $a l$. An overview on fracture behaviour of FGM was conducted by Shanmugavel et al.,. Other reviews on functionally graded materials available in the literature are: review study on research and development by Cherradi et al., [N. Cherradi et al], Tilbrook et al., also conducted review study on crack propagation in functionally graded materials [M. T. Tilbrook et al]. A number of researches have also been conducted in the areas of analysis and modeling work on functionally graded material; some of these work can be found in [Y. Hattori et al]. There are still more to be done in terms of research to improve the performance of manufacturing processes of FGM.

\section{Future Research Direction}

Functionally graded material is an excellent advanced material that will revolutionize the manufacturing world in the 21st century. There are a number of roadblocks for realizing this objective. Cost is a major problem, with substantial part of the cost expended on powder processing and fabrication method. Solid freeform fabrication technique and Friction Stir Processing offers a greater advantage for producing FGM, but there are still lots of issues that need to be resolved with this promising technology. More research needs to be conducted on improving the performance of SFF processes through extensive characterization of functionally graded material in other to generate a comprehensive database and to develop a predictive model for proper process control. Further work should also be done to improve the process control through development of more powerful feedback control for overall FMG fabrication process improvement (i.e. full automation). This will improve the overall performance of the process, bring down the cost of FGM and improve reliability of the fabrication process.

\section{Conclusions}

Functionally graded materials are very important in engineering and other applications but the cost of producing these materials makes it prohibitive in some applications. This study presents an overview on FGM, various fabrication methods were highlighted with solid freeform providing the best advantage over other processes because of the manufacturing flexibility it offers. An overview of different application areas is also presented and how the application area can further be enhanced and also extended by bringing down the fabrication cost through improving the most promising fabrication method.

\section{References}

B. Craig (1989), Limitations of Alloying to Improve the threshold for Hydrogen Stress Cracking of Steels Hydrogen Effects on Material Behavior, Moran, Wyoming, USA., pp. 955-963.

R. K. Rajput (2008),. Manufacturing technology: (manufacturing processes), Laxmi publications (P) limited, New Delhi, India,.

D. Hon, and Shiraishi (2001), Wood and cellulose chemistry, 2nd ed. (New York: Marcel Dekker).

S. S. Wang (1983), Fracture mechanics for delamination problems composite materials, Journal of Composite Materials, , vol. 17(3), pp. 210-223.

M. Niino, T. Hirai and R. Watanabe(1992), The functionally gradient materials, J Jap Soc Compos Mat, vol.13, pp. 257264.

Report on Fundamental study on relaxation of thermal stress for high temperature material by tailoring the graded structure, Department of Science and Technology Agency,

P. Shanmugavel, G. B. Bhaskar, M. Chandrasekaran, P. S. Mani and S. P. Srinivasan (2012), An overview of fracture analysis in functionally graded materials, European Journal of Scientific Research, vol.68 No.3, pp. 412-439.

A. A. Atai, A. Nikranjbar, and R. Kasiri (2012), Buckling and post-buckling Behaviour of semicircular functionally graded material arches: a theoretical study, Proceedings of the Institution of Mechanical Engineers, Part C: Journal of Mechanical Engineering Science, vol. 226, pp. 607-614. 
R. Knoppers, J. W. Gunnink, J. Van den Hout, and W. Van Vliet, The reality of functionally graded material products, TNO Science and Industry, The Netherlands, pp 38-43.

M. Ivosevic R. Knight, S. R. Kalidindi, G. R. Palmese and J. K. Sutter (2005), Solid particle erosion resistance of thermally sprayed functionally graded coatings for polymer matrix composites, Surface Coat Tech.

Functionally Graded Material by European virtual institute of knowledge-based multifunctional material, Accessed on 10th of January 2012, Available at http://www.kmmvin.eu/Research/FunctionallyGradedMa terials/tabid/68/Default.aspx

J. F. Groves, and H. N. G. Wadley, Functionally graded materials synthesis via low vacuum directed vapor deposition, Composites Part B: Engineering, vol. 28.

M. M. Nemat-Alla1, M. H. Ata, M. R. Bayoumi, and W. KhairEldeen (2011), Powder metallurgical fabrication and microstructural investigations of Aluminium/Steel functionally graded material, Materials Sciences and Applications, vol. 2, pp. 1708-1718.

F. Watari, A. Yokoyama, H. Matsuno, R. Miyao, M. Uo, T. Kawasaki, M. Omori, and T. Hirai (2001), Fabrication of functionally graded implant and its biocompatibility, functionally graded materials in the 21st century: a workshop on trends and forecasts. Boston, Kluwer Academic, pp. 187-190.

J. Zhu, Z. Lai, Z. Yin, J. Jeon, and S. Lee, Fabrication of ZrO2$\mathrm{NiCr}$ functionally graded material by powder metallurgy, Materials Chem,

Y. Watanabe, Y. Inaguma, H. Sato, and E. A. Miura-Fujiwara, (2008), Novel fabrication method for functionally graded materials under centrifugal force: the centrifugal mixedPowder method, Materials, Vol. 2, No. 4, pp.2510-2525.

B. Kieback, A. Neubrand, and H. Riedel, (2003), Processing techniques for functionally graded materials, Materials Science and Engineering, pp. 81-105.

X. Lin and T. M. Yue (2005), Phase formation and microstructure evolution in laser rapid forming of graded SS316L/Rene88DT alloy, Mater Sci Engg, vol. A402, pp.294-306.

M. A. Boboulos, CAD-CAM \& Rapid Prototyping Application

Evaluation, $\mathrm{PhD} \&$ Ventus publishing Aps, accessed online on $1^{\text {st }}$ March 2012, available at www.bookBoom.com.

D. W. Hutmacher, M. Sittinger, and M. V. Risbud (2004), Scaffold-based tissue engineering: rationale for computeraided design and solid freeform fabrication systems, Trends Biotechnol, vol.22 (7), pp. 354-62.

Y. T. Pei and J. Th. M. De Hosson, (2000), Functionally graded materials produced by laser cladding, Acta mater. Vol. 48, pp. 2617-2624.

W. Jiang, R. Nair and P. Molian (2005) Functionally graded mold inserts by laser-based flexible fabrication: processing modeling, structural analysis, and performance evaluation, J Mater Process Tech, vol. 166, and pp.286-293.

W. Liu and J. N. Dupont, (2003),, Fabrication of functionally graded TiC/Ti composites by Laser Engineered Net Shaping, Scripta Materialia, vol. 48, pp. 1337-1342.

K. A. Mumtaz, and N. Hopkinson, (2007), Laser melting functionally graded composition of waspaloy and zirconia powders, Journal of Materials Science, vol. 42, pp. 76477656

T. R. Jackson, H. Liu, N. M. Patrikalakis, U. E. M. Sachs, and M. J. Cima, (1999), Modeling and designing functionally graded material components for fabrication with local composition control, Materials and Design, vol.20, pp.6375.

X. C. Li, J. Stampfl, and F. B. Prinz, Mechanical and Thermal
Expansion Behaviour of Laser Deposited Metal Matrix Composites of Invar and TiC, Materials Science and Engineering A, vol. 282, (2000), pp.86-90.

V. E. Beal, P. Erasenhiran, C. H. Ahrens, and P. Dickens, Evaluating the Use of Functionally Graded Materials Inserts Produced by Selective Laser Melting on the Injection Moulding of Plastic Parts, Proceedings of ImechE Part B Journal of Engineering Manufacture, vol. 221(6), pp. 945-954.

D. Dimitrov, K. Schreve, N. De Beer, (2006), Advances in Three Dimensional Printing - State of the Art and Future Perspectives, Rapid Prototyping Journal, vol. 12(3), pp. 136-147.

A. Bandyopadhyay, B. V. Krishna, W. Xue, S. Bose, (2008), Application of Lens to manufacture porous and functionally graded structures for load bearing implants, Journal of Materials Science Materials in Medicine.

M. Erdal S. Dag, Y. Jande and C. M. Tien, (2009), Manufacturing of Functionally Graded Porous Product Produced by Selective Laser Sintering, Material Science Forum, vol. 631-632, pp. 253-258.

H. Chung and S. Das, (2008), Functionally graded Nylon11/silica nanocomposites Produced by Selective Laser Sintering, Materials Science and Engineering A, vol. 487(12), 251-257.

M. M. Gasik( 2010), Functionally graded materials: bulk processing techniques, International Journal of Materials and Product Technology, vol. 39, (1-2), pp. 20 - 29

L. Marin, (2005), Numerical solution of the Cauchy problem for steady-state heat transfer in two dimensional functionally graded materials, Int J Solids Struct, vol. 42, pp. 4338-4351.

W. Pompea, H. Worch, M. Epple, W. Friess, M. Gelinsky, P. Greil, U. Hempele, D. Scharnweber, and K. Schulte, (2008), Functionally graded materials for biomedical applications, Materials Science and Engineering, vol. A362, pp. 40-60.

S. Matsuo, F. Watari, and N. Ohata(2001), Fabrication of functionally graded dental composite resin post and core by laser lithography and finite element analysis of its stress relaxation effect on tooth root, Dental Mater J, vol.20(4), pp. 257-274.

F. Watari, A. Yokoyama, M. Omori, T. Hirai, H. Kondo, and M. Uo, et al. ,2004), Biocompatibility of materials and development to functionally graded implant for biomedical application. Compos Sci Technol, vol. 64, pp. 893908.

L. Lu, M. Chekroun, O. Abraham, V. Maupin and G. Villain, (2008), Mechanical properties estimation of functionally graded materials using surface waves recorded with a laser interferometer, NDT \&amp; E International, Volume 44, Issue 2, Pages 169-177.

E. Müller, C. Drašar, J. Schilz, and W.A. Kaysser, (2003), Functionally graded materials for sensor and energy applications, Materials Science and Engineering: A, vol. 362, pp. 17-30.

M. Niino, K. Kisara and M. Mori, (2005), Feasibility study of FGM technology in space solar power systems (SPSS), Mater Sci Forum, vol. 492, pp. 163-168.

M. Malinina, T. Sammi, M. Gasik, (2005), Corrosion resistance of homogeneous and FGM coatings, Mater Sci Forum, vol.492-493, (2005), pp. 305-310.

A. Xing, Z. Jun, H. Chuanzhen and Z. Jianhua, (1995), Development of an advanced ceramic tool material functionally gradient cutting ceramics, Mater Sci Engg A, vol. 248, (1998), pp. 125-31.

A. Kawasaki, R. Watanabe, (2002), Thermal fracture behavior of metal/ ceramic functionally graded materials, Engg Fract Mech, vol. 69, pp.1713-28. 
B. Woodward and M. Kashtalyan, (2012), Performance of functionally graded plates under localised transverse loading, Compos Struct, doi:10.1016/j.compstruct.2012.02.012

B-L. Wang, and Y-W. Mai, (2006), A periodic array of cracks in functionally graded materials subjected to transient loading, International Journal of Engineering Science, vol. 44(5-6), pp. 351-364.

K. Tohgo, T. Suzuki, and H. Araki(2005), Evaluation of Rcurve behavior of ceramic-metal functionally graded materials by stable crack growth, Engineering Fracture Mechanics, vol.72(15), pp. 2359-2372.

Z.-H. Jin, and R.H. Dodds Jr(2004), Crack growth resistance behavior of a functionally graded material: computational studies, Engineering Fracture Mechanics, vol. 71(12),pp. 1651-1672.

H-P. Xiong, , A. Kawasaki, Y-S. Kang, and R. Watanabe (2005), Experimental study on heat insulation performance of functionally graded metal/ceramic coatings and their fracture behavior at high surface temperatures, Surface and Coatings Technology, vol. 194(2-3), pp. 203-214.

J. Chen, and Z. Liu (2005), On the dynamic behavior of a functionally graded piezoelectric strip with periodic cracks vertical to the boundary, International Journal of Solids and Structures, vol. 42(11-12), pp. 3133-3146.

X. Jin, L. Wu, L. Guo, H. Yu, and Y. Sun, (2009), Experimental investigation of the mixed-mode crack propagation in $\mathrm{ZrO} 2 / \mathrm{NiCr}$ functionally graded materials, Engineering Fracture Mechanics, vol. 76(12), pp. 1800-1810.

Z. Cheng, D. Gao, and Z. Zhong (2010), Crack propagating in functionally graded coating with arbitrarily distributed material properties bonded to homogeneous substrate, Acta Mechanica, vol. 23(5), pp. 437-446.

R. Rodríguez-Castro, R. C. Wetherhold, and M. H. Kelestemur, (2008),Microstructure and mechanical behavior of functionally graded Al A359/SiCp composite, Materials Science and Engineering: A, vol. 323(1-2), pp. 445-456.

C-E. Rousseau, and H. V. Tippur (2001), Influence of elastic gradient profiles on dynamically loaded functionally graded materials: cracks along the gradient, International Journal of Solids and Structures, vol. 38(44-45), pp. 78397856.

L-Z. Wu, L-C. Guo, and Z-G. Zhou, (2005), Dynamic behavior of a finite crack in the functionally graded materials, Mechanics of Materials, vol. 37(11), pp. 1153-1165.

S. A. Meguid, X. D. Wang, and L. Y. Jiang, (2002), On the dynamic propagation of a finite crack in functionally graded materials, Engineering Fracture Mechanics, vol. 69(14-16), pp. 1753- 1768.
V. Birman and L.W. Byrd, (2007), Modeling and analysis of Functionally graded materials and structures, Appl Mech Rev, vol. 60(1-6), pp.195-216.

N. Cherradi, A. Kawasaki, M. Gasik, , (1994), Worldwide trends in functional gradient materials research and development, Compos Eng, vol. 8, pp.883-894.

M. T. Tilbrook, R. J. Moon, and M. Hoffman (2005), Crack propagation in graded composites, Compo Sci Tech, vol. 65, pp.201-220.

Y. Hattori, H. Sato, E. Miura-Fujiwara, and Y. Watanabe (2010), Estimation of the Cooling Rate Distribution by means of Lamellar Spacing of Al- Al2Cu Eutectic Structure during Fabrication of FGM under Centrifugal Force, Functionally Graded Materials, Vol. 24, pp. 17-22.

X. Y. Koua, G. T. Pars, and S. T. Tana(2012), Computer-Aided Optimal design of functionally graded materials using a procedural model and particle swarm optimization, Design, vol. 44, pp. 300-310.

M. Nemat-Alla K. I. E. Ahmed and I. Hassab-Allah (2009), Elastic-plastic analysis of two-dimensional functionally graded materials under thermal loading, International Journal of Solids and Structures, vol. 46(14- 15), pp. 27742786.

P. Zhu, and K. M. Liew (2011), Free vibration analysis of moderately thick functionally graded plates by local Kriging meshless method, Composite Structures, vol. 93.

J. S. Kumar, B. S. Reddy and C. E. Reddy (2011), Nonlinear bending analysis of functionally graded plates using higher order theory, International Journal of Engineering Science and Technology (IJEST, Vol. 3(4), pp. 3010-3022.

J. S. Kumar, B. S. Reddy, C. E. Reddy and K. V. K. Reddy (2011), Nonlinear bending analysis of functionally graded plates using higher order theory, International Journal of Engineering Science and Technology (IJEST, Vol. 3 (1), pp. 279-288.

X. Y. Kou, and S. T. Tan (2012), Microstructural modelling of functionally graded materials using stochastic Voronoi diagram and B-Spline representations, International Journal of Computer Integrated Manufacturing, vol. 25(2), pp 177-188.

E. Ruocco, and V. Minutolo (2012), Two-dimensional stress analysis of multiregion functionally graded materials using a field boundary lement model, Composites Part B: Engineering, vol. 43(2), pp. 663-672.

A. O. Olatunji., S. K. S. Boetcher, and T. R. Cundari (2012), Thermal conduction analysis of layered functionally graded materials, Computational Materials Science, vol. 54, pp. 329-335. 